\title{
High Prevalence of Subclinical Mastitis and Multidrug Resistant Staphylococcus aureus Are a Threat to Dairy Cattle Production in Kiboga District (Uganda)
}

\author{
Keneth Iceland Kasozi ${ }^{1,2}$, John Bosco Tingiira2 ${ }^{2}$ Patrick Vudriko ${ }^{*}$ \\ ${ }^{1}$ Central Diagnostic Laboratory, Department of Pharmacy, Clinics and Comparative Medicine, College of \\ Veterinary Medicine, Animal Resources and Biosecurity, Makerere University, Kampala, Uganda \\ ${ }^{2}$ Kiboga District Regional Veterinary Laboratory, Department of Production and Marketing, Kiboga District Local \\ Government, Kiboga, Uganda \\ Email: vpato@vetmed.mak.ac.ug, vpato2009@gmail.com
}

Received 27 February 2014; revised 27 March 2014; accepted 3 April 2014

Copyright $@ 2014$ by authors and Scientific Research Publishing Inc.

This work is licensed under the Creative Commons Attribution International License (CC BY).

http://creativecommons.org/licenses/by/4.0/

(c) $\underset{\mathrm{EY}}{\mathrm{C}}$ Open Access

\section{Abstract}

Subclinical mastitis (SCM) is one of the major factors affecting the productivity of dairy cattle all over the world. This study established the burden of SCM and determined the potent antibacterial formulation for control of Staphylococcus aureus (SA) related SCM in selected dairy cattle farms in Kiboga district. A total of 124 dairy cattle from 12 farms were screened for SCM using California Mastitis Test (CMT) from Kiboga Town-Council, Kapeke and Lwamata sub-counties. The offending bacteria were cultured and the antibiogram of SA was carried out using antibacterial susceptibility by the modified Kirby-Bauer disc diffusion method. Additional qualitative data on the factors that predispose cows to SCM was obtained through questionnaires and observation of milking Practice. The prevalence of SCM in the three sub-counties was $87.9 \%$. Over $70 \%$ of the dairy cattle screened for SCM had more than 2 udder quarters affected. The majority $(90 \%)$ of SCM was caused by mixed bacterial infections: Coagulase negative staphylococci $(64.4 \%)$ and $S A(16.6 \%)$ being the most prevalent. All the farmers (100\%) lacked knowledge on SCM, udder towels, teat dipping and drug cow therapy. Overall, $71.4 \%$ of SA isolated was multi-drug resistant. There was a high level of resistance against penicillin $(100 \%)$, neomycin $(85.7 \%)$ and tetracycline $(71.4 \%)$. In contrast, all the above isolates were susceptible to Trimethoprim-Sulphamethazole. In conclusion, the high burden of SCM and emergence of multidrug resistant SA are one of the constraints to dairy production in Kiboga district. Therefore, sensitization of dairy farmers in Kiboga district on proper hygienic, appropriate milking techniques and dry cow therapy using potentiated sulfonamide in-

\footnotetext{
${ }^{*}$ Corresponding author.
}

How to cite this paper: Kasozi, K.I., et al. (2014) High Prevalence of Subclinical Mastitis and Multidrug Resistant Staphylococcus aureus Are a Threat to Dairy Cattle Production in Kiboga District (Uganda). Open Journal of Veterinary Medicine, 4, 35-43. http://dx.doi.org/10.4236/ojvm.2014.44005 
tra-mammary preparations are highly recommended in SA associated SCM.

\author{
Keywords
}

\title{
Antibacterial Susceptibility, Dairy Cattle, Subclinical Mastitis, Staphylococcus aureus
}

\section{Introduction}

Subclinical mastitis (SCM) continues to be a silent nightmare to the economic propensity of the dairy sector in Uganda. In fact, $75 \%$ of economic losses of mastitis is caused by SCM [1] [2], thus contributing to the poor performance associated with the dairy sector in Uganda. As the disease takes toll on the dairy industry in Uganda, early detection and management remains elusive due to lack of diagnostic services at local government levels. This has been accentuated by the weak extension services and poor animal health seeking behavior of farmers. Moreover, recent studies [1] [3] have revealed that dairy farmers lacked knowledge on the ideal milking techniques, milking hygiene and SCM. The major contagious mastitis causative pathogens are Staphylococcus aureus (SA) and Streptococcus agalactiae (SAG), while the minor contagious pathogen is Corynebacterium bovis (CB) [1]. The major environmental mastitis causative pathogens are other Streptococci (OS) and Coliforms (CO), while Coagulase negative Staphylococci (CNS) are minor environmental pathogens [1] [4] [5].

SA is the fourth most common subclinical mastitis pathogen in Uganda [6]. SA is considered one of the most problematic mastitis pathogens due to its strong virulence factors [4]. Its $\alpha$-haemolysis virulence factor was reported [2] to cause fatal gangrenous mastitis. The infection due to SA is easily spread within a herd, and cows get infected primarily during the milking process. The most commonly isolated CNS species in SCM are S. epidermidis, S. simulans, S. chomogenes, S. xylosus and S. haemolyticus; they are generally considered less virulent than SA thus causing milder forms of SCM [4]. Therefore, udder tissue damage due to CNS is limited, hence the prognosis is fairly good. Most CNS mastitis can be prevented through good milking procedures, accurate management measures and overall hygiene [1]. SCM caused by CNS can be locally treated with antibiotics during the period. However, of concern is the increasing prevalence of $\beta$-lactamase-producing CNS [2] which are resistant to penicillins. Although SA is often sensitive to penicillin, such treatment may be unsuccessful due to the bacteria's ability to hide deep in the udder tissue, thus leading to chronic SCM [1] [4].

Dairy cattle with chronic infection or with penicillin resistant bacteria should be eliminated to avoid new infections. Various antibiotics-based intra-mammary infusions for both dry-cow therapy and treatment of clinical mastitis are available on the Ugandan market. However, the increasing emergence of antibiotic resistant pathogens in the country [2] [7] [8] is further suspected to complicate the effectiveness of mastitis treatment. The treatment of clinical mastitis by farmers using antibacterial drugs without seeking prescription was reported [2] [7] as predisposing factor to the emergence of drug resistance and treatment failures. Therefore, this study established the prevalence of SCM and determined the potent antibacterial formulation for possible control of SA related SCM in selected dairy cattle farms in Kiboga district.

\section{Materials and Method}

\subsection{Study Design}

This was a basic cross-sectional study that was carried out between August and November 2012 to determine the prevalence, causes and choice of antibacterial drug for effective control of SA related SCM in Kiboga district. The study area included three randomly selected sub-counties of Kapeke, Lwamata, and Kiboga Town-Council.

\subsection{Sample Size Determination}

The sample size for this study was determined using the formula by Martinez et al., [9] at a previous prevalence of sub-clinical mastitis of $86.2 \%$ at dairy cattle level [5]. Furthermore, 5\% Error at 95\% confidence was considered for the calculation. The list of dairy farms in each sub-county was obtained from the District Veterinary Of- 
fice and used as a sampling frame for random selection of farms for sampling. A total of 12 farms were chosen with 2 from Kapeke, 7 from the Town Council, and 3 from Lwamata. The selection criteria for these farms were based on herd structure, district veterinary records and accessibility as advised by the District Veterinary Office. All lactating dairy cattle in the selected herd that had no history of clinical mastitis were eligible for selection. However, lactating cattle that were on antibiotic therapy in the last one month prior to the study were excluded.

\subsection{Selection of Cows and SCM Screening Using CMT}

In each herd, the number of lactating dairy cattle that were sampled was determined by the herd size. A preliminary visit was made to the farms within the sub-counties of Kiboga district to ascertain the average herd size for small, medium and large herd categories in the area. Individual herds of dairy cattle were selected randomly and the entire herd was selected if it met the inclusion criteria. The cattle were restrained in a crush to avoid injury whenever found available on the farms. Each teat and its orifice were thoroughly cleaned with cotton wool soaked in $70 \%$ ethanol starting with teats that were furthest. Using a gloved hand, approximately $2 \mathrm{ml}$ of milk from each quarter (starting with the furthest teats) were squirted in corresponding quadrants of the CMT paddle. An equivalent volume ( $2 \mathrm{ml}$ ) of CMT reagent was then added to each quadrant and mixed gently. The results were then interpreted qualitatively depending on the thickness of the gel formed [10].

\subsection{Collection of Milk Samples for Microbial Analysis}

All dairy cattle that were lactating were included in the study after analyzing their individual clinical history against the inclusion criteria. Milk samples were collected from all the quarters for bacterial culture and isolation. The teats and the orifices of the quarters were cleaned again using cotton wool soaked in $70 \%$ ethanol as described above. Approximately $2 \mathrm{ml}$ of milk was stripped using clean gloved hands into sterile sample vial from the affected quarter(s) to make a composite sample. Each sample was labeled and the information regarding the cow was entered in the data sheet. The sample was immediately transferred into a cool box maintained at $5^{\circ} \mathrm{C}$ with ice packs and then taken to Kiboga District Veterinary Laboratory for bacterial analysis.

\subsection{Bacterial Analysis}

\subsubsection{Microbial Culture of Milk Samples}

Bacterial culture and isolation was done according to methods by Mornica [11] with minor modifications [1]. Briefly, $50 \mu \mathrm{l}$ of composite milk was inoculated on 5\% sheep blood agar medium and incubated for 18 - 20 hrs at $37^{\circ} \mathrm{C}$. Identification of the bacteria was carried out basing on colony characteristics such as size, shape, color and hemolysis patterns [1].

\subsubsection{Antimicrobial Susceptibility Test for SA}

This was done using Mueller-Hinton agar (MHA) according to Kirby-Bauer disc diffusion method [12]. The SA inoculum for each dairy farm was prepared as follows; one SA colony was mixed with $100 \mu \mathrm{l}$ of distilled sterile water in sterile tubes. The mixture (inoculant) was applied on MHA plates and surface spread using a sterile spreader. Antibiotic discs were then applied using sterile forceps. The zones of inhibition were measured using a ruler and Oxford mathematical set divider, and the resultant diameters compared to the European Committee on Antimicrobial Susceptibility Testing [13] reference values for the different antimicrobial agents.

\subsection{Questionnaire and Observations of Farm Practice}

An open ended questionnaire was used to determine the hygiene status, occurrence of clinical mastitis as well as antibiotic use practices on the farm. The key lead questions were on milking practices, udder hygiene, personnel hygiene, knowledge on mastitis prevention and therapy. Observation of hygiene and milking practices were made for purposes of validation of the farmers' responses.

\subsection{Data Analysis and Presentation}

The data was analyzed descriptively using SPSS Version 16 software and presented as frequency tables. 


\section{Results}

\subsection{Demographics}

A total of 124 dairy cattle were screened for SCM from three sub-counties in Kiboga district. The majority (40\%) of the dairy cattle sampled were from Lwamata while the rest were from Kapeke (30\%) and Town Council (30\%). Majority (70\%) of the farms had over 20 heads of dairy cattle in both Lwamata and Kapeke. However, the Town Council was dominated by only small-holder dairy farmers who owned less than 10 heads of cattle. The overall proportion of lactating dairy cattle in the herd for the three sub-counties was $40 \%$.

\subsection{Prevalence of SCM}

The prevalence of SCM for the three sub-counties ranged from $80 \%$ to $94.59 \%$. Kapeke sub-county had the highest burden of SCM at a prevalence of $94.59 \%$ followed by Town Council with $91.89 \%$; Lwamata recorded a prevalence of $80 \%$. The district prevalence was found to be at $87.9 \%$ (Table 1 ).

\subsection{Number of Udder Quarters Affected by SCM}

Over 70\% of the dairy cattle screened for SCM had more than 2 quarters affected. Majority (54.8\%) of them had all the 4 quarters diagnosed with SCM while $21.0 \%$ of the cows had 3 quarters affected. However, $6.5 \%$ and $13.7 \%$ of the dairy cattle tested had SCM in 1 and 2 quarters of the udder respectively. Only $4 \%$ of all the dairy cattle screened tested negative for SCM (Table 2).

Table 1. Distribution of dairy cattle sampled for SCM across the study area.

\begin{tabular}{cccc}
\hline Sub-county & $\begin{array}{c}\text { No. of dairy cattle } \\
\text { screened }\end{array}$ & $\begin{array}{c}\text { No. of dairy cattle with } \\
\text { SCM }\end{array}$ & \% of dairy cattle SCM \\
\hline Kapeke & 37 & 35 & 94.59 \\
Town council & 37 & 34 & 91.89 \\
Lwamata & 50 & 40 & 80 \\
Total & 124 & 109 & $87.9 \%{ }^{\mathrm{a}}$ \\
\hline
\end{tabular}

Key: ${ }^{\mathrm{a}}=$ Overall prevalence for the district; No. = Number.

Table 2. Number of udder quarters affected by SCM in the different dairy farms.

\begin{tabular}{|c|c|c|c|c|c|c|c|}
\hline Location & Farm & $1 \mathrm{Qtr}$ & 2 Qtrs & 3 Qtrs & 4 Qtrs & C.Qtrs & $\mathrm{N}$ \\
\hline \multirow{5}{*}{ Kapeke } & $\mathrm{F} 1$ & 0 & 1 & 3 & 13 & 0 & 17 \\
\hline & F2 & 0 & 3 & 8 & 9 & 0 & 20 \\
\hline & F3 & 0 & 0 & 0 & 3 & 0 & 3 \\
\hline & F4 & 0 & 0 & 1 & 4 & 0 & 5 \\
\hline & F5 & 1 & 4 & 1 & 2 & 0 & 8 \\
\hline \multirow[t]{5}{*}{ Town Council } & F6 & 0 & 2 & 1 & 1 & 0 & 4 \\
\hline & F7 & 0 & 0 & 1 & 3 & 0 & 4 \\
\hline & F8 & 0 & 0 & 1 & 3 & 0 & 4 \\
\hline & $\mathrm{F} 12$ & 1 & 1 & 2 & 4 & 1 & 9 \\
\hline & F9 & 4 & 1 & 7 & 16 & 2 & 30 \\
\hline \multirow[t]{2}{*}{ Lwamata } & F10 & 0 & 1 & 1 & 5 & 1 & 8 \\
\hline & F11 & 2 & 4 & 0 & 5 & 1 & 12 \\
\hline Total & & 8 & 17 & 26 & 68 & 5 & 124 \\
\hline Percentage & & 6.5 & 13.7 & 21.0 & 54.8 & 4.0 & 100 \\
\hline
\end{tabular}

Key: $\mathrm{F}_{1}-\mathrm{F}_{12}=$ farms; 1 Qtr-Dairy cattle in which one quarter of the udder had SCM, 2 Qtrs-Dairy cattle in which two quarters of the udder had SCM, 3 Qtrs-Dairy cattle in which three quarters of the udder had SCM, 4 Qtrs-Dairy cattle in which all the Four quarters had SCM and C. Qtrs-Dairy cattle in which all the 4 quarters had no SCM, N is the sample size from individual farms sampled. 


\subsection{Degree of Severity of SCM Based on CMT Scores}

Over $60 \%$ of the cows tested had CMT scores ranging from 1 to 2 in the milk. However, $16.13 \%$ of the dairy cattle had more severe SCM as evidenced by scores of 3 in the milk as shown below (Table 3).

\subsection{Bacterial Pathogens Isolated from Milk in the Different Dairy Farms Visited}

The most prevalent bacterial pathogens associated with SCM were Staphylococci such as Coagulase negative Staphylococci (64.42\%) and SA (16.56\%). Streptococci species where below 10\%; SAG at 3.68\% and 5.52\% for the other Streptococci. However, other bacterial pathogens isolated included CB (6.13\%), and CO (3.68\%) as shown in the Table 4.

\subsection{Susceptibility of SA against Common Antibacterial Drugs Used for Treatment of Mastitis}

Majority (71.4\%) of SA isolated were resistant to at least four antibacterial drugs. The prevalence of drug resistance was over $70 \%$ in the different farms in the Town Council compared to those in Kapeke and Lwamata in which resistance ranged from $42.6 \%$ to $57.1 \%$. The SA isolated from all the 7 farms were highly resistant to Penicillin $(100 \%)$ followed by Neomycin (85.7\%) and tetracycline (71.4\%). Resistance to Streptomycin and Gentamicin were $42.6 \%$ and $28.6 \%$ respectively. Trimethoprim-Sulphamethoxazole (Sulfamethoxazole), was potent and no resistance was recorded in SA isolated from the 7 farms in Kiboga district (Table 5).

\subsection{Hygiene Status, Milking Practices and Management of Mastitis on the Dairy Farms}

The factors that could have contributed to high prevalence of SCM included; lack of knowledge on SCM (100\%), cleaning towels $(100 \%)$, teat dipping $(100 \%)$, dry cow therapy $(100 \%)$ and teat pulling $(100 \%)$ during milking as well as no usage of disinfectant (100\%). Over $50 \%$ of the farmers had poor farm hygiene and visible dirt on the udder of lactating cows. Antimastitic formulations containing penicillins (60\%), tetracycline (30\%) sulfonamides (5\%) and aminoglycoside (5\%) were used for treatment of clinical mastitis. Unfortunately, $68 \%$ of the treatment was done by the farmers and herdsmen while only $32 \%$ was done by veterinarians (Table 6).

Table 3. Severity of subclinical mastitis in the various farms based on CMT scores.

\begin{tabular}{|c|c|c|c|c|c|c|}
\hline \multirow[b]{2}{*}{ Location } & \multicolumn{5}{|c|}{ CMT score } & \multirow[b]{2}{*}{$\mathrm{N}$} \\
\hline & Farm & 0 & 1 & 2 & 3 & \\
\hline \multirow{5}{*}{ Kapeke } & $\mathrm{F}_{1}$ & 7 & 26 & 12 & 23 & 68 \\
\hline & $\mathrm{F}_{2}$ & 16 & 27 & 22 & 15 & 80 \\
\hline & $\mathrm{F}_{3}$ & 0 & 4 & 4 & 4 & 12 \\
\hline & $\mathrm{F}_{4}$ & 1 & 8 & 6 & 5 & 20 \\
\hline & $\mathrm{F}_{5}$ & 13 & 11 & 3 & 5 & 32 \\
\hline \multirow[t]{5}{*}{ Town council } & $\mathrm{F}_{6}$ & 5 & 9 & 2 & 0 & 16 \\
\hline & $\mathrm{F}_{7}$ & 1 & 8 & 6 & 1 & 16 \\
\hline & $\mathrm{F}_{8}$ & 1 & 8 & 3 & 4 & 16 \\
\hline & $\mathrm{F}_{12}$ & 10 & 11 & 9 & 6 & 36 \\
\hline & $\mathrm{F}_{9}$ & 29 & 46 & 35 & 10 & 120 \\
\hline \multirow[t]{2}{*}{ Lwamata } & $\mathrm{F}_{10}$ & 7 & 17 & 5 & 3 & 32 \\
\hline & $\mathrm{F}_{11}$ & 17 & 17 & 10 & 4 & 48 \\
\hline Total & & 107 & 192 & 117 & 80 & 496 \\
\hline Percentage & & 21.57 & 38.71 & 23.59 & 16.13 & 100 \\
\hline
\end{tabular}

Key: $\mathrm{F}_{1}-\mathrm{F}_{12}$-farms, 0-negative, no thickening, 1-distinct thickening, no gel formation; 2-distinct thickening, slight gel formation; 3-gel is formed; $\mathrm{N}$ is the sample size. 
Table 4. Prevalence of bacteria isolated from milk in the different dairy farms.

\begin{tabular}{|c|c|c|c|c|c|c|}
\hline Farm (F) & SA & CNS & SAG & OS & $\mathrm{CB}$ & $\mathrm{CO}$ \\
\hline $\mathrm{F}_{1}$ & 5 & 12 & 2 & 3 & 0 & 3 \\
\hline $\mathrm{F}_{2}$ & 11 & 18 & 3 & 2 & 0 & 1 \\
\hline $\mathrm{F}_{3}$ & 0 & 3 & 0 & 0 & 0 & 1 \\
\hline $\mathrm{F}_{4}$ & 2 & 5 & 0 & 1 & 0 & 0 \\
\hline $\mathrm{F}_{5}$ & 1 & 8 & 0 & 0 & 0 & 0 \\
\hline $\mathrm{F}_{6}$ & 0 & 4 & 0 & 0 & 0 & 0 \\
\hline $\mathrm{F}_{7}$ & 1 & 4 & 0 & 0 & 0 & 0 \\
\hline $\mathrm{F}_{8}$ & 0 & 4 & 0 & 0 & 0 & 0 \\
\hline $\mathrm{F}_{9}$ & 6 & 20 & 0 & 2 & 10 & 1 \\
\hline $\mathrm{F}_{10}$ & 1 & 8 & 1 & 1 & 0 & 0 \\
\hline $\mathrm{F}_{11}$ & 0 & 12 & 0 & 0 & 0 & 0 \\
\hline $\mathrm{F}_{12}$ & 0 & 7 & 0 & 0 & 0 & 0 \\
\hline Total: & 27 & 105 & 6 & 9 & 10 & 6 \\
\hline Prev. & 16.56 & 64.42 & 3.68 & 5.52 & 6.13 & 3.68 \\
\hline
\end{tabular}

Key: $\mathrm{F}_{1}-\mathrm{F}_{12}$-farms; $\mathrm{SA}=$ Staphylococcus aureus, CNS = Coagulase negative staphylococcus; SAG = Streptococcus agalactiae, OS = Other Streptococcus, $\mathrm{CB}=$ Corynebacteriumbovis; $\mathrm{CO}=$ Coliforms; Prev. = prevalence; total number of bacterial isolates = 163 .

Table 5. Susceptibility of Staphylococcus aureus against common antibacterial drugs used for treatment of mastitis in Uganda.

\begin{tabular}{|c|c|c|c|c|c|c|c|c|}
\hline Location & Farm & PG10C & Т30C & G10C & CX5C & SXT25 & N10C & S10C \\
\hline \multirow{2}{*}{ Kapeke } & $\mathrm{F}_{1}$ & $\mathrm{R}$ & $\mathrm{R}$ & $\mathrm{S}$ & $\mathrm{R}$ & $\mathrm{S}$ & S & S \\
\hline & $\mathrm{F}_{2}$ & $\mathrm{R}$ & $\mathrm{R}$ & $\mathrm{S}$ & $\mathrm{R}$ & $\mathrm{S}$ & $\mathrm{R}$ & $\mathrm{S}$ \\
\hline \multirow{3}{*}{ Town Council } & $\mathrm{F}_{4}$ & $\mathrm{R}$ & $\mathrm{R}$ & $\mathrm{R}$ & $\mathrm{R}$ & S & $\mathrm{R}$ & $\mathrm{R}$ \\
\hline & $\mathrm{F}_{5}$ & $\mathrm{R}$ & $\mathrm{R}$ & S & $\mathrm{R}$ & $\mathrm{S}$ & $\mathrm{R}$ & $\mathrm{R}$ \\
\hline & $\mathrm{F}_{7}$ & $\mathrm{R}$ & $\mathrm{R}$ & $\mathrm{R}$ & $\mathrm{R}$ & $\mathrm{S}$ & $\mathrm{R}$ & $\mathrm{S}$ \\
\hline \multirow{3}{*}{ Lwamata } & $\mathrm{F}_{9}$ & $\mathrm{R}$ & $\mathrm{S}$ & S & $\mathrm{R}$ & S & $\mathrm{R}$ & $\mathrm{S}$ \\
\hline & $\mathrm{F}_{10}$ & $\mathrm{R}$ & $\mathrm{S}$ & $\mathrm{S}$ & $\mathrm{R}$ & $\mathrm{S}$ & $\mathrm{R}$ & $\mathrm{R}$ \\
\hline & $\% R D$ & 100 & 71.4 & 28.6 & 100 & 0 & 85.7 & 42.6 \\
\hline
\end{tabular}

Key: $\mathrm{F}_{1}-\mathrm{F}_{10}=$ farm; $\mathrm{R}=$ resistant, $\mathrm{S}=$ susceptible; $\mathrm{PG} 10 \mathrm{C}=$ penicillin $\mathrm{G} ; \mathrm{T} 30 \mathrm{C}=$ tetracycline; $\mathrm{G} 10 \mathrm{C}=$ gentamicin; $\mathrm{CX} 5 \mathrm{C}=$ cloxacillin; $\mathrm{SXT} 25=$ trimethoprimsulphamethazole; N10C = neomycin; S10C = streptomycin; \% RD = Resistance per drug basis.

\section{Discussion}

The current prevalence of SCM in Kiboga district (87.9\%) was higher than what has been previously reported. Byarugaba et al. [6] found a prevalence of 61.3\% in Jinja district. In a related study, Abrahmsén [5] reported prevalence of SCM of 86.2\% among dairy cattle reared in urban and peri-urban areas of Kampala. Byarugaba et al. [6], carried out the study on mastitis on dairy farms that were predominantly managed under zero grazing system unlike the current study where cattle were kept under extensive system. Within Kiboga dis- 
Table 6. Hygiene status, milking practices and management of mastitis on the farms.

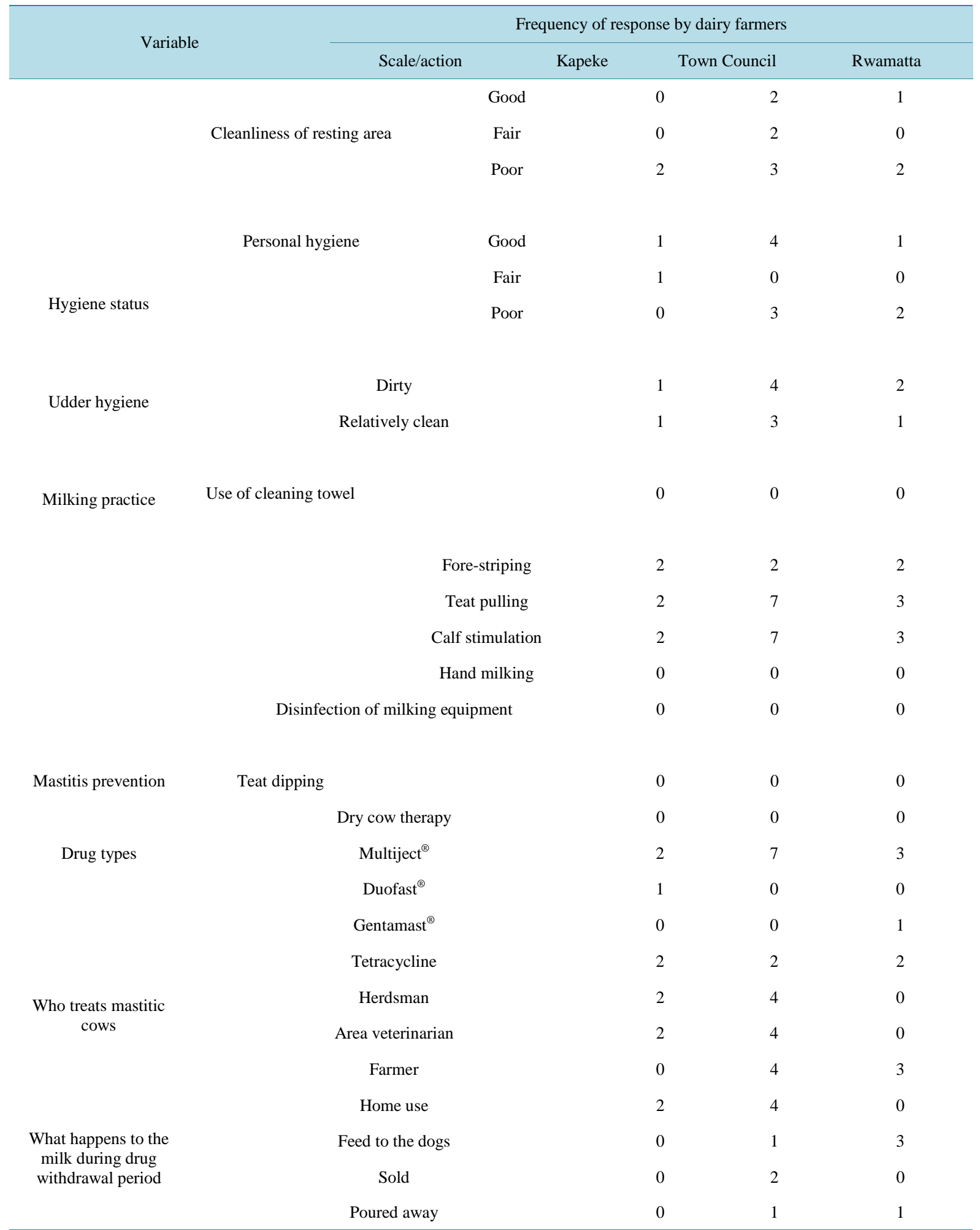

Key: Multiject ${ }^{\circledR}$ (neomycin, streptomycin and penicillin); Duofast ${ }^{\circledR}$ (trimethoprim and sulfamethazole); Gentamast ${ }^{\circledR}$ (gentamicin); n = 12 farms.

trict, variations in prevalence of SCM among different sub-counties could be due to the extent of accessibility to extension services and clean water. Highly contaminated water carries bacteria that can gain entry into the udder 
to cause SCM when used for cleaning the teats especially with the absence of post teat dipping.

The study also revealed that $70 \%$ of the dairy cattle tested had SCM in more than 2 quarters of the udder and $54.8 \%$ having all the 4 quarters affected. This has a serious implication on economics of milk production in the affected dairy farms. It is recognized that SCM can cause reduction in milk production from the affected quarter by up to $60 \%$ [1]. Moreover, at least $60 \%$ of the dairy cattle tested had CMT scores ranging from 1 to 2 . This indicates that majority of the dairy cattle that tested positive had severe SCM. Similarly, Hand et al. [14] reported significant milk production losses associated with increase in SCC due to SCM. Other economic losses attributed to SCM include increase in treatment cost and culling [15].

In this study, the major constraints to mastitis control were primarily farmers' poor hygienic practices, largely attributed to lack of knowledge on the disease. No wonder, all the farmers assessed had no prior knowledge about SCM although they were aware of clinical mastitis. Poor environment and udder hygiene characterized by extensive soiling of the udder and the teats with manure were amongst factors predisposing cattle to SCM. This was further exacerbated by poor personnel hygiene; contaminated water coupled with lack of cleaning towels thus compounding the spread of contagious and environmental pathogens that cause SCM. Moreover, the few dairy farms that used milking salve had high level of bacterial load during preparation due to poor hygiene. Unfortunately, such poor hygiene also leads to possible contamination of milk thus arousing genuine milk safety concern.

While Uganda Dairy Development Authority (DDA), urges all dairy producers to use metallic buckets, a majority (10/12) of the farms assessed use plastic milking jars which are difficult to effectively clean thus encouraging bacterial multiplication. Bacterial culture results indicate that the most prevalent causative pathogens associated with SCM were Staphylococci (over 80\%). Anri [1] also reported that Staphylococci are the dominant causes of SCM and are associated with low CMT scores. The contagious pathogens isolated were SA (16.56\%), SAG (3.68\%), CB (6.13\%) which accounts for the high prevalence of SCM in the dairy cattle and being propagated by the poor hygienic practices at the dairy farms visited. However, environmental pathogens isolated included: CNS (64.42\%), OS (5.52\%), and CO (3.68\%). Since CO are usually associated with clinical mastitis, this proportion was probably due to the contamination of the milk samples during sample collection [1].

Antibacterial sensitivity of SA isolated from the 7 dairy farms revealed $100 \%$ resistance against penicillin followed by neomycin (85.7\%) and tetracycline (71.4\%). At least $71.4 \%$ of SA isolated from the above farms were resistant to at least four antibacterial drugs. This multi-drug resistance is a real threat to effective control of the disease since the options are limited. Such high prevalence of resistance by udder pathogens was previously reported [6]. The highest level of resistance was registered from samples obtained from the Town Council (over $50 \%$ ), suggestive of high drug pressure and irrational use of antibiotics. Indeed, over $80 \%$ of the farmers used Multiject $^{\circledR}$ (penicillin, neomycin and streptomycin) and tetracycline for treatment of mammary and systemic bacterial diseases. The sale of antibiotics over-the-counter without prescription [16] has offered unprecedented access to the drugs by farmers. No wonder, only $30 \%$ of the farmers relied on veterinarians for treatment but the majority treated their animals with the aid of herdsmen. Such treatments were carried without strict adherence to dosage requirements and treatment period due to lack of technical knowledge among farmers and herdsmen considering their low level of education. Such abuse of drugs is responsible for the emergence of multi-drug resistant SA [17] which is a threat to both animal and public health. However, Trimethoprim-sulphamethazole was $100 \%$ effective against penicillin, tetracycline and aminoglycoside resistant SA.

\section{Conclusion}

The high burden of SCM and emergence of multidrug resistant SA are one of the constraints to dairy production in Kiboga district. Therefore, sensitization of dairy farmers in Kiboga district on proper hygiene, appropriate milking techniques and dry cow therapy based on the results of antibiotic sensitivity tests are highly recommended in SA associated SCM. Further research is also needed to identify the most appropriate extension materials on mastitis that can have a significant impact on effective control of the disease.

\section{Acknowledgements}

The authors would like to acknowledge the contribution of Japan International Cooperation Agency (JICA) through the Animal Disease Control project towards the success of this study. 


\section{References}

[1] Anri, A. (2012) Manual for Mastitis Control in Developing Countries. Japan Livestock Technology Association. 37-56.

[2] Byarugaba, D.K., Kisame, R. and Olet, S. (2011) Multi-Drug Resistance in Commensal Bacteria of Food of Animal Origin in Uganda. African Journal of Microbiology Research, 5, 1539-1548.

[3] Vaarst, M., Byarugaba, D.K., Nakavuma, J. and Laker, C. (2007) Participatory Livestock Farmer Training for Improvement of Animal Health in Rural and Peri-Urban Smallholder Dairy Herds in Jinja, Uganda. Tropical Animal Health and Production, 39, 1-11. http://dx.doi.org/10.1007/s11250-006-4439-8

[4] Pyörälä, S. (1995) Staphylococcal and Streptococcal Mastitis. In: Sandholm, M., Honkanen-Buzalski, T., Kaartinen, L., Pyörälä, S., Eds., The Bovine Udder and Mastitis, Faculty of Veterinary Medicine, University of Helsinki, Helsinki, 143-148.

[5] Abrahmsén, M. (2012) Prevalence of Subclinical Mastitis in Dairy Farms in Urban and Peri-Urban Areas of Kampala, Uganda. Second Cycle. SLU, Department of Clinical Sciences, Uppsala. http://stud.epsilon.slu.se/4213/1/Abrahms\%C3\%A9n_m_120507.pdf

[6] Byarugaba, D.K., Nakavuma, J.L., Vaarst, M. and Laker, C. (2008) Mastitis Occurrence and Constraints to Mastitis Control in Smallholder Dairy Farming Systems in Uganda. Livestock Research for Rural Development, 20, 1. http://www.lrrd.org/lrrd20/1/byar20005.htm

[7] Nakavuma, J., Byarugaba, D.K., Musisi, L.N. and Kitimbo, F.X. (1994) Microbiological Diagnosis and Drug Resistance Patterns of Infectious Causes of Mastitis. Uganda Journal of Agricultural Sciences, 2, 22-28.

[8] Kintu, A., Byarugaba-Karuhize, D. and Nalwanga, D.K. (2000) Mastitis in Peri-Urban Zero-Grazing Dairy Farming around Kampala. Uganda Veterinary Journal, 6, 45-50.

[9] Martinez, G.R. (1988) An Appraisal of Mastitis and the Potential for Its Control in Dairy Herds on the Savannah of Bogota. PhD Thesis, University of Reading, Reading.

[10] Mellenberger, R. and Roth, C.J. (2000) California Mastitis Test (CMT), Fact Sheet. Department of Animal Sciences, Michigan State University and Department of Dairy Science, University of Wisconsin-Madison.

[11] Monica, C. (2006) District Laboratory Practice in Tropical Countries, Part 2. 2nd Edition, 62-70, 132-143, 157-234.

[12] Quinn, P.J., Carter, M.E., Markey, B. and Carter, G.R. (1994) Clinical Veterinary Microbiology. Wolfe Publishing, London.

[13] EUCAST (2012) Disk Diffusion Method for Antimicrobial Susceptibility Testing. Version 2.1. www.eucast.org

[14] Hand, K.J., Godkin, A. and Kelton, D.F. (2012) Milk Production and Somatic Cell Counts: A Cow-Level Analysis. Journal of Dairy Science, 95, 1358-1362. http://www.sciencedirect.com/science/article/pii/S0022030212000926 http://dx.doi.org/10.3168/jds.2011-4927

[15] Jemeljanovs, A., Cerina, S. and Konosonoka, I.H. (2010) Economic Losses Resulting from Subclinical Mastitis in Dairy Cows. http://www.eaap.org/previous annual meetings/2010crete/papers/18 jemeljanovs.pdf

[16] Byarugaba, D.K. (2004) A View on Antimicrobial Resistance in Developing Countries and Responsible Risk Factors. International Journal of Antimicrobial Agents, 24, 105-110. http://dx.doi.org/10.1016/j.ijantimicag.2004.02.015

[17] Nihar, N.M., Priyaranjan, D., Shaswati, S.P., Laxmi, N.S., Siddharth, R. and Hemant, K.P. (2013) Isolation and Antibiogram of Staphylococcus, Streptococcus and Escherichia coli Isolates from Clinical and Subclinical Cases of Bovine Mastitis. Veterinary World, EISSN: 2231-0916. www.veterinaryworld.org/Vol.6/Oct-2013/9.pdf 